\title{
Current and Future Research in Active Control of Lightweight, Flexible Structures Using the X-56 Aircraft
}

\author{
John J. Ryan* John T. Bosworth ${ }^{\dagger} \quad$ John J. Burken ${ }^{\ddagger}$ \\ and Peter M. Suh ${ }^{\S}$ \\ NASA Dryden Flight Research Center, Edwards, CA, 93523
}

\begin{abstract}
The X-56 Multi-Utility Technology Testbed aircraft system is a versatile experimental research flight platform. The system was primarily designed to investigate active control of lightweight flexible structures, but is reconfigurable and capable of hosting a wide breadth of research. Current research includes flight experimentation of a Lockheed Martin designed active control flutter suppression system. Future research plans continue experimentation with alternative control systems, explore the use of novel sensor systems, and experiments with the use of novel control effectors. This paper describes the aircraft system, current research efforts designed around the system, and future planned research efforts that will be hosted on the aircraft system.
\end{abstract}

\section{Introduction}

The X-56 (Lockheed Martin, Bethesda, Maryland) Multi-Utility Technology Testbed (MUTT) aircraft system was designed to be a modular experimental research platform. The system is reconfigurable and capable of hosting a wide breadth of research. The primary purpose of the system is to conduct experimental research into the modeling and control of aeroservoelastic effects. This research will enable a paradigm shift in aircraft design. Current design methodologies add stiffening elements to raise the velocity at which flutter and other undesirable unsteady vibrational modes occur. New methods under research are exploring design methodologies which use active structural control to suppress the unsteady modes. The methods enable lighter aircraft and more slender wing designs which lead to higher fuel efficiency.

This paper presents an overview of the X-56 system, current research efforts, and planned future research efforts. The current efforts include investigating the use of nontraditional sensors and active control systems to suppress undesirable aeroservoelastic modes. The efforts include simulation studies and in-flight experimentation and test. Future planned research efforts include experimentation with and investigations of active control schemes, nontraditional sensors, and novel control surface designs. Section II presents an overview of the system, the variable configuration of the aircraft, currently available sensors, and the ground control system. Section III presents current research efforts including work being conducted by Lockheed Martin, MUSYN (Minneapolis, Minnesota), and the National Aeronautics and Space Administration (NASA). Each uses differing control design techniques in attempt to suppress aeroservoelastic modes. Among the techniques used are Linear Quadratic Gaussian, Tracker, $\mathcal{H}_{\infty}, \mu$, and Linear Parameter Varying control designs. Section IV discusses plans for future research and testing of sensors, control effectors, and feedback control techniques. Section V concludes the paper.

\footnotetext{
*Aerospace Engineer, Controls and Dynamics Branch, P.O. Box 273/Mailstop 4840D, AIAA Member.

$\dagger$ Aerospace Engineer, Controls and Dynamics Branch, P.O. Box 273/Mailstop 4840D, AIAA Senior Member.

$¥$ Aerospace Engineer, Controls and Dynamics Branch, P.O. Box 273/Mailstop 4840D, AIAA Senior Member.

$\S$ Graduate Student Trainee, Controls and Dynamics Branch, P.O. Box 273/Mailstop 4840D, AIAA Student Member.
} 


\section{The X-56 Vehicle System}

The X-56 aircraft was designed by Lockheed Martin, under contract for the Air Force Research Laboratory (AFRL)(Wright-Patterson Air Force Base, Ohio), to be a versatile, modular, remotely piloted aircraft. The aircraft system consists of two center-bodies, four wing sets, a ground control station, and a storage trailer. Each wing set can be attached to either center-body. Figure 1 depicts the system. The two center bodies are identical measuring 90 inches in length and 38 inches in width. The center bodies house fuel tanks, on board system electronics, and a ballistic parachute recovery system. Power for the aircraft is provided by two JetCat P400 turbojets (JetCat USA, LLC, Paso Robles, California) mounted on the fuselage. Hard-points on the center body provide a means to mount a third engine or a boom for a joined-wing configuration.

The ballistic parachute recovery system allows experimentation at the extreme edges of the vehicle flight envelope; if catastrophic flutter or other loss-of-control phenomenon are encountered, the parachute system will return the aircraft to the ground with minimal damage.

The four wing sets consist of one stiff-wing set and three identical flexible wing sets. Three flexible wing sets were constructed because of the aggressive nature of the flight-test plans. The onset speed of the aeroservoelastic modes of the stiff-wing set was designed to lie outside of the flight envelope. The flexible wing sets were purposely designed to place the body freedom flutter, symmetric-wing-bending-torsion, and antisymmetric-wing-bending-torsion mode onset speeds well within the flight envelope. The design enables in-flight experimentation of active flutter control and active flutter suppression.

Each wing set has ten control surfaces, which are depicted in Figure 2. Two body-flaps lie adjacent to the interface of the center-body and wings. Four ailerons are distributed across each wing. Wing housed water tanks provide a capability to vary the mass properties of the vehicle and alter the vibrational characteristics during flight. The capability is used to explore the robustness of automatic control systems.

The aircraft is instrumented with six accelerometers, an embedded global positioning system/inertial navigation system (EGI), hot film anemometers, a pitot static system, and an out-the-nose camera. The accelerometer locations are depicted in Figure 2. The accelerometers are distributed across the platform with one on the fore and aft sections of the center-body, and one on the leading and trailing edges of each wing tip. This distribution allows for measurement of the aircraft aeroservoelastic modes. The EGI is mounted in the fuselage near the center of gravity. The hot film anemometers are mounted on the leading edge of each wing.

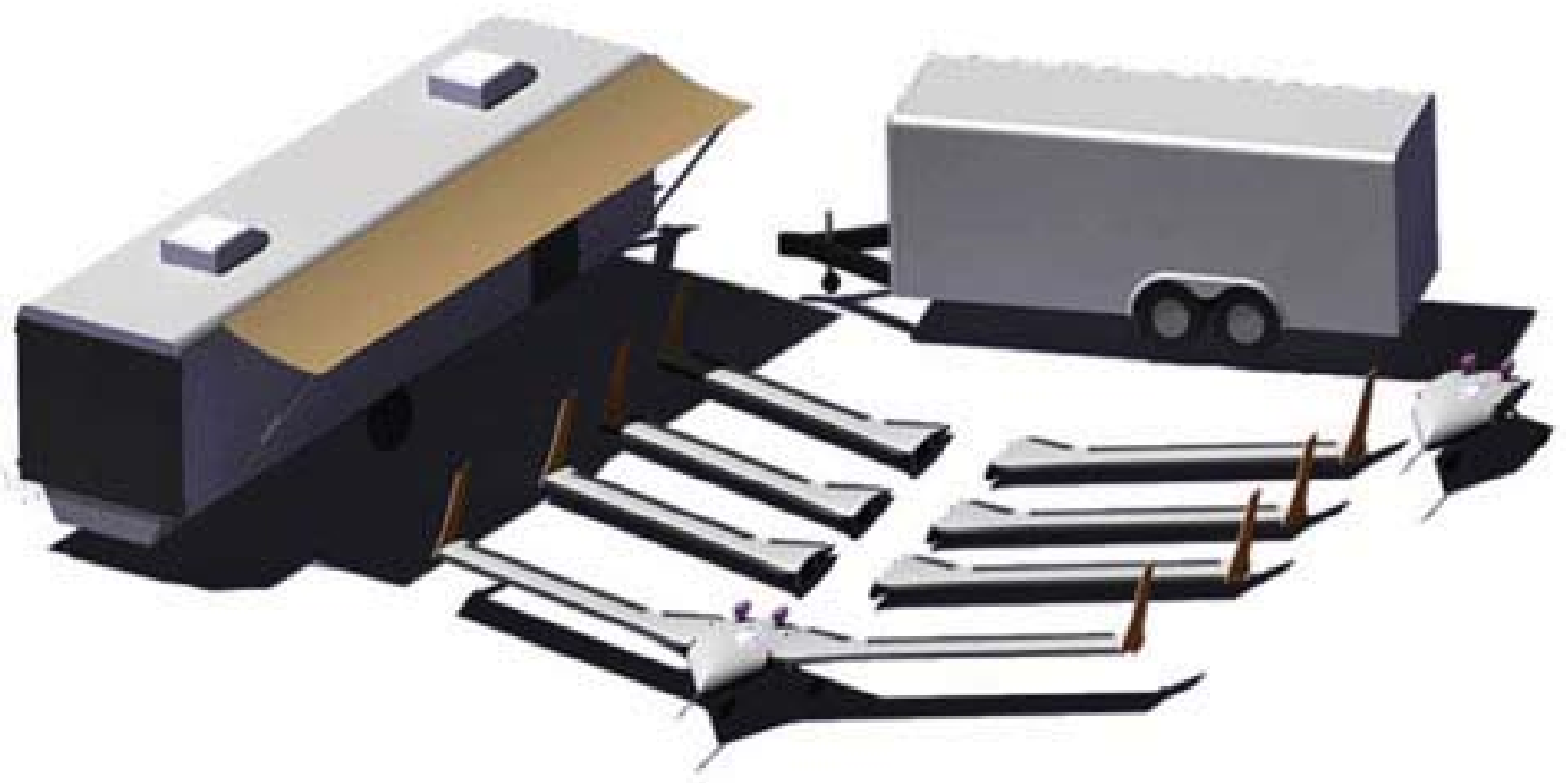

Figure 1. The X-56 aircraft system consists of two center-bodies, four wing sets, a ground control station, and a storage trailer. 


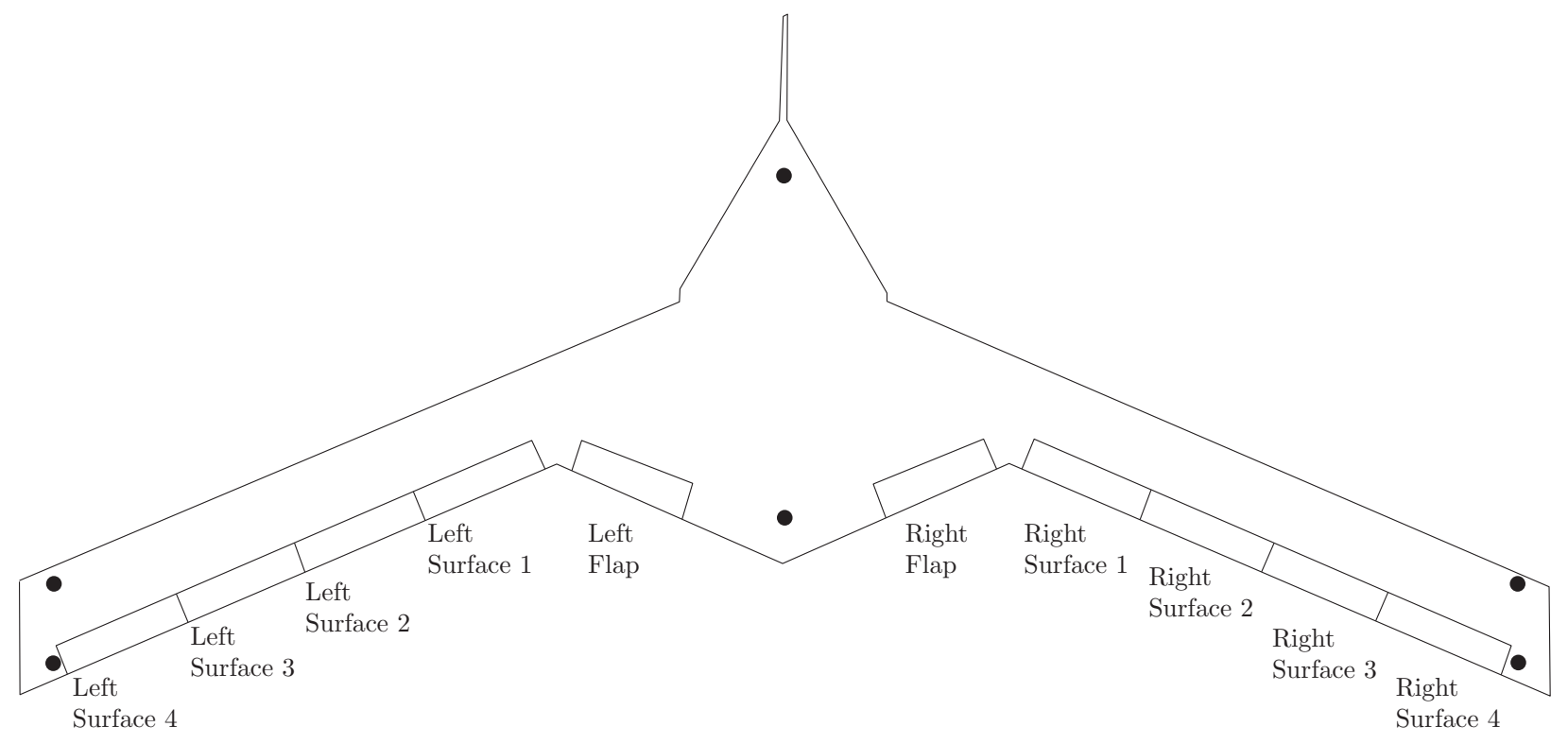

Figure 2. Control surfaces and accelerometers of the X-56 aircraft. Accelerometer locations are indicated with large dots. Control surfaces are labeled.

The ground control station provides three main functions: command and control of the vehicle, monitoring of in-flight experimentation, and nonlinear simulation of the vehicle. Pilot and co-pilot stations provide command and control through stick and rudder inceptors, out-the-nose video with overlaid heads-up-display, and configurable glass-cockpit instrumentation. Flight-test engineering stations provide insight into in-flight experiments through multiple configurable displays.

The ground control station incorporates a full nonlinear pilot-in-the-loop simulation using the same pilot, co-pilot, and flight-test engineer stations as used during flight. The ground control station is useful for pilot training, flight-test engineer training, flight rehearsal, and flight-test-card development. The simulation can be electronically connected to the aircraft systems to form a full hardware-in-the-loop simulation. The hardware-in-the-loop simulation is a versatile platform for software and hardware test, and verification and validation. Aircraft ownership will be passed to the NASA Dryden Flight Research Center (Edwards, California) during 2014.

The inherent modularity of the system will enable a vast array of efficient future research activities. Such research may include different wing-sets and tail sections. Experimental sensors, control surfaces, and wing shapes can easily be incorporated onto the system for flight experimentation. More information on the X-56 system can be found in the report by Beranek. ${ }^{1}$

\section{Current Research Efforts}

There are currently multiple research efforts underway involving the X-56 aircraft. Most are investigating potential control design techniques capable of suppressing aeroservoelastic modes. Such control designs enable a paradigm shift in aircraft design. Current design methodologies add stiffening elements to raise the velocity at which flutter and other undesirable vibration modes occur. Research is exploring design methodologies using active structural control to suppress the unsteady modes. The methodologies will enable lighter aircraft and more slender wing designs which lead to higher fuel efficiency. There is a rich body of literature covering this research such as that by Hjartarson, ${ }^{2}$ Mangalam, ${ }^{3}$ Karpel, ${ }^{4}$ and the references therein.

\section{A. Air Force Research Laboratory / Lockheed Martin}

The Air Force Research Laboratory is in the midst of experimental research to determine the effectiveness of active flutter suppression control systems. AFRL has contracted Lockheed Martin to design, synthesize, integrate, and flight-test such control systems on the X-56 aircraft. The research goal is to demonstrate that 
aeroelastic instability can be accurately predicted and suppressed through the use of active control systems. The research will enable use of lightweight high-aspect-ratio wings which will reduce the overall aircraft weight and reduce aircraft drag. ${ }^{5}$

In conjunction with the NASA Dryden Flight Research Center, Lockheed Martin has conducted multiple flight tests. The first flight occurred on July $26,2013^{6}$ in the stiff-wing configuration. The flight lasted 14 minutes while the flight crew successfully evaluated the aircraft handling qualities at 60 and 70 knots. A total of eight flights in the stiff-wing configuration have been completed. Lockheed Martin is now transitioning to a flexible-wing configuration flight-test campaign in which active suppression of aeroelastic instabilities will be demonstrated and predicted onset speeds will be verified. Flight-test results are not yet available for publication.

In previous research Lockheed Martin built and flight-tested five smaller scale vehicles in order to demonstrate the accuracy of modeling techniques and the ability of an active flight control system to subdue aeroservoelastic modes. The models demonstrated good correlation between models and flight-test data. Results from this work can be found in the published report. ${ }^{7}$

\section{B. MUSYN}

Another research effort is being conducted by MUSYN Incorporated. MUSYN has designed a flutter suppression control system for the X-56 aircraft using a rate-bounded linear parameter varying (LPV) control design technique. ${ }^{2}$ The NASA Dryden Flight Research Center provided linear models of the X-56 aircraft, in the flexible-wing configuration, at seven flight conditions to MUSYN. Each consists of 130 states and models 14 structural modes. The models were constructed from a finite element model developed in NASTRAN (MSC Software Corporation, Newport Beach, California) and an aerodynamic model developed in ZAERO (ZONA Technology Incorporated, Scottsdale, Arizona) to produce coupled structural and aerodynamic forces used to represent the flight dynamics in state-space models. ${ }^{8}$ Figure 3 depicts the natural frequencies and damping values of the first five modes as a function of scaled velocity. The system is stable at scaled velocities below 0.8. At higher scaled-velocities, the damping-ratio becomes positive indicating unstable modes. The body-freedom-flutter mode becomes unstable at approximately 0.8 scaled-velocity. The symmetric and anti-symmetric wing bending-torsion modes become unstable at approximately 0.9 and 0.95 scaled-velocity respectively. The transition points are labeled as $\mathrm{A}, \mathrm{B}$, and $\mathrm{C}$ in the figure.

The control design objective was to stabilize the model and augment the damping of the first four structural modes. These modes occur between 3.2 and $10 \mathrm{~Hz}$.

The MUSYN design process was to reduce the order of the models, design $\mathcal{H}_{\infty}$ point controllers, and then design a full envelope LPV controller. During the process, the models were successfully reduced to 15 states while maintaining the model characteristics essential for control system design. The design used measurements of roll rate, pitch rate, yaw rate, the center body accelerometer at the trailing edge, and the two accelerometers at the trailing edge wing tips. The LPV design was scheduled as a function of velocity. Frequency dependent weighting functions penalized the control commands, the rate outputs, and the acceleration outputs. The resulting closed loop system reached the design objectives stabilizing the system and augmenting the damping of the four structural modes.

The same weighting functions were used to synthesize a rate-bounded LPV controller. The LPV control design methodology provides robustness and performance guarantees across the design envelope. The Matlab toolbox LPVTools, developed by MUSYN, was used for the LPV synthesis. The resulting full envelope control system achieved performance close to that of the $\mathcal{H}_{\infty}$ point design controllers. Detailed results of this work can be found in a paper by Hjartarson. ${ }^{2}$

\section{NASA Dryden Flight Research Center}

In one effort a Linear Quadratic Gaussian Tracker control design methodology is being used. A theoretical development of the control design methodology can be found in numerous references such as that by Arvanitis. ${ }^{9}$ The methodology was applied to an X-56 linear model developed at an unstable velocity. The model has 130 state and is unstable in multiple flutter modes. The model inputs are the ten control surfaces. The model outputs are the accelerations of the aft end of the wing tips, acceleration of the aft center body, roll angle, pitch angle, and yaw angle. These outputs are inputs of the LQG-tracker control system which commands the control surface positions. Figure 4 displays the response to a pitch command of the stabilized $\mathrm{X}-56$ models. The doublet command is indicated by a dashed black line. The response of the system is 

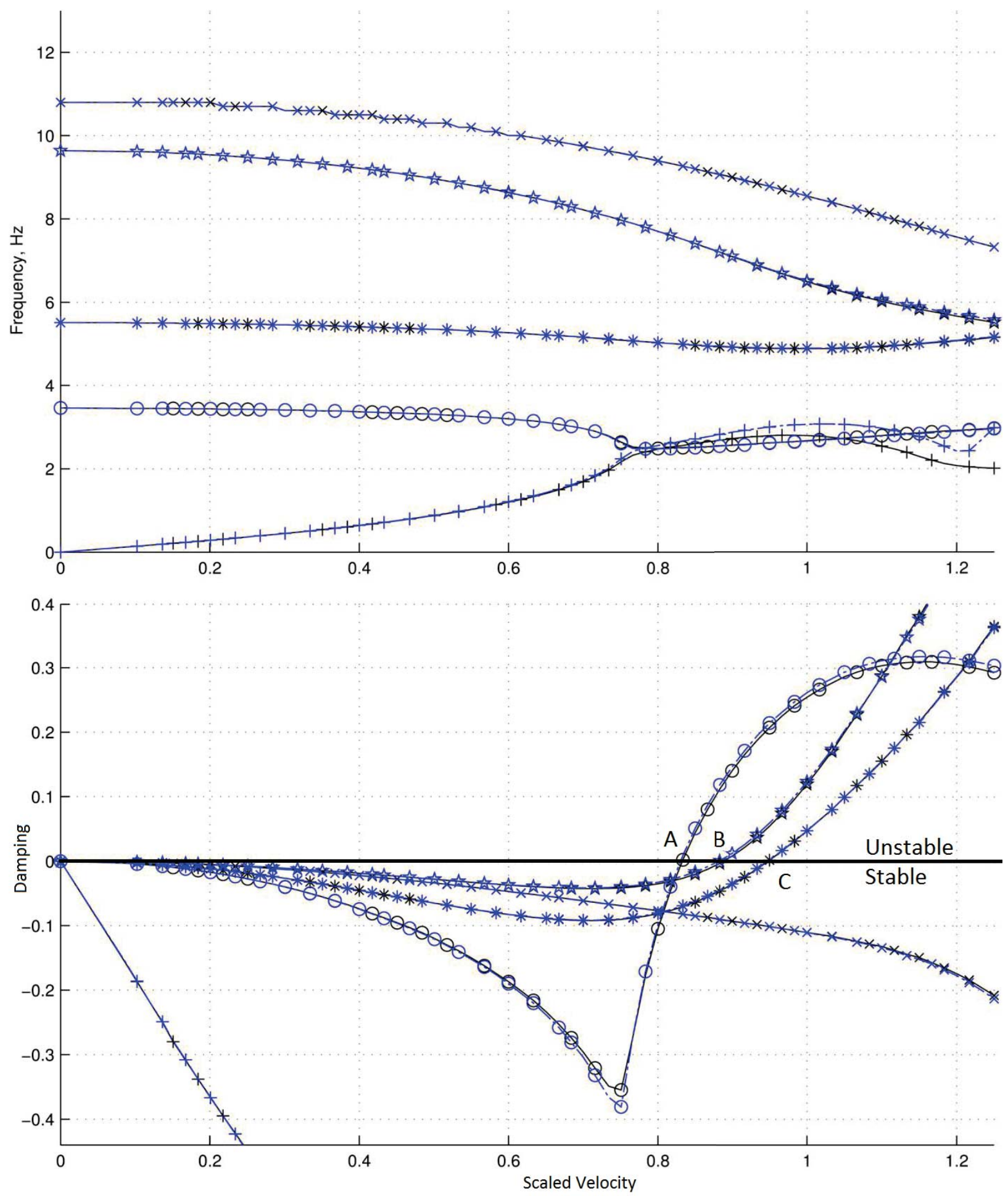

Figure 3. Natural frequencies and damping values as a function of scaled velocity. A positive damping value indicates instability. Point A indicates the point of body-freedom-flutter instability. Point B indicates the point of symmetric wing bending mode instability. Point $\mathrm{C}$ indicates the point of anti-symmetric wing bending mode instability. 


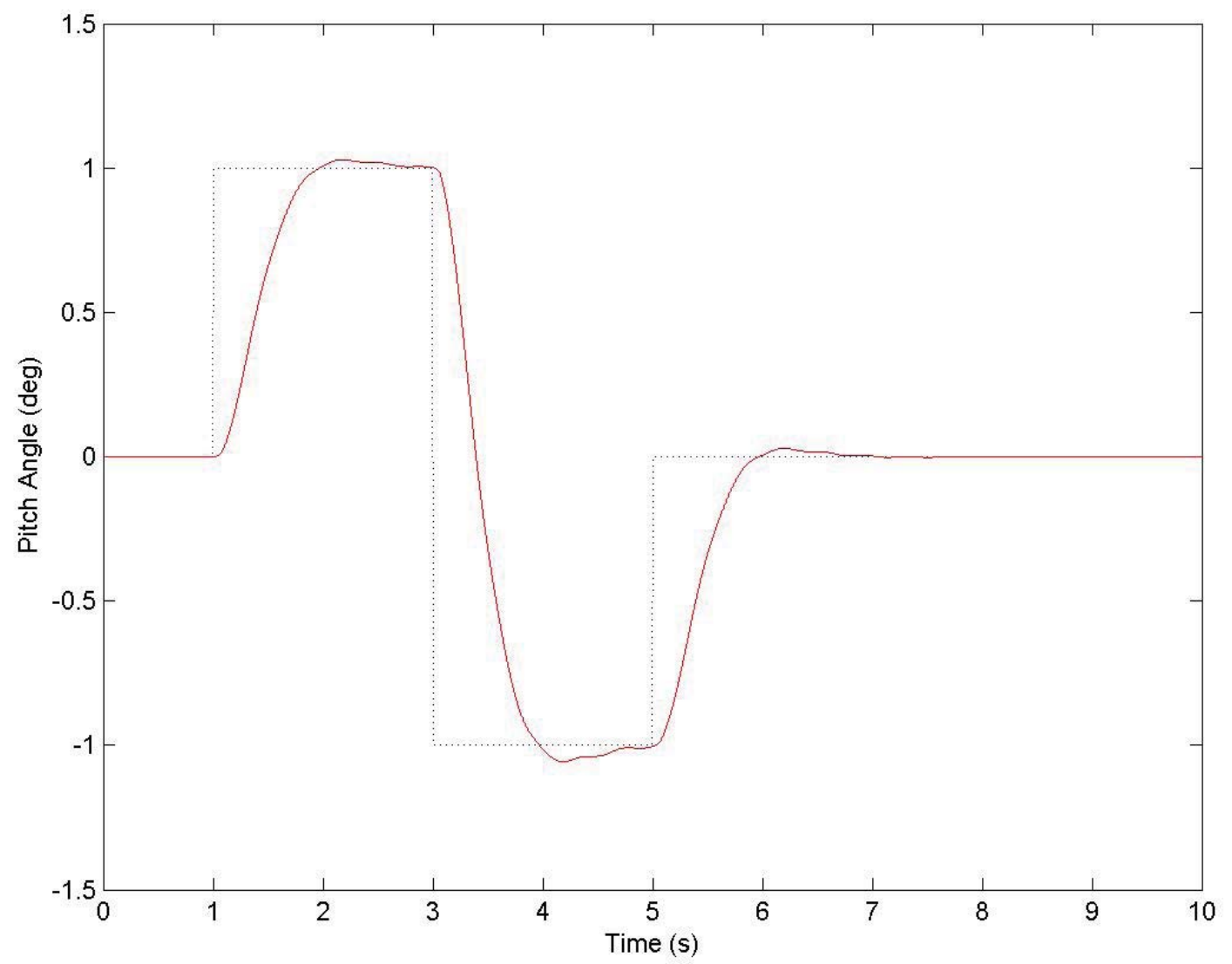

Figure 4. X-56 aircraft response to a pitch command doublet. The black dashed line depicts the command. The solid red line represents the response of the closed-loop system. 
depicted by a red line. The system response is smooth with approximately a one-second rise time and small overshoot. The small oscillations are due to the residual energy of the damped flutter modes.

Figure 5 depicts the surface movement of the stabilized system during the doublet response. The surface movements are symmetrical across the longitudinal axis and hence the surface movements of only one wing is shown. The upper most plot depicts the movement of the body flaps. The remaining plots depict the movement of the inner most to outer most wing surfaces. The gross movement of the body-flap and innermost wing control surface are opposite in direction than the second, third, and fourth control surfaces. The movement is due to the combined objectives of damping the flutter modes and following the pitch command. The small oscillations are due to the active suppression of the flutter mode near $3 \mathrm{~Hz}$ as seen in Figure 3. The largest surface movements are from the inner-most wing surfaces. The movements are less than twenty degrees. All other surfaces have smaller movement. Similar results are found across all design points.

Another research effort at the NASA Dryden Flight Research Center is attempting to suppress aeroservoelastic modes by controlling model displacements of the system; that is the displacement of each mode of the system. In the control scheme, fiber optic strain-sensor measurements and a modal filter are used to estimate modal displacements. An active control system commands the modal displacements to suppress the aeroservoelastic modes.

The research effort is currently at a simulation stage. A fiber optic strain-sensor system has not yet been installed on the X-56 aircraft. The effort assumes the fiber optic system will provide 1500 strain measurements at a sampling rate of $100 \mathrm{~Hz}$ from 6 fiber optic lines installed on the X-56 wings.

Such a system has already been installed on other research aircraft including the NASA Ikhana aircraft (General Atomics Aeronautical Systems Incorporated, San Diego, California). ${ }^{10}$ The system is far lighter than conventional strain-sensor systems, is easier to install, and provides high resolution measurements at
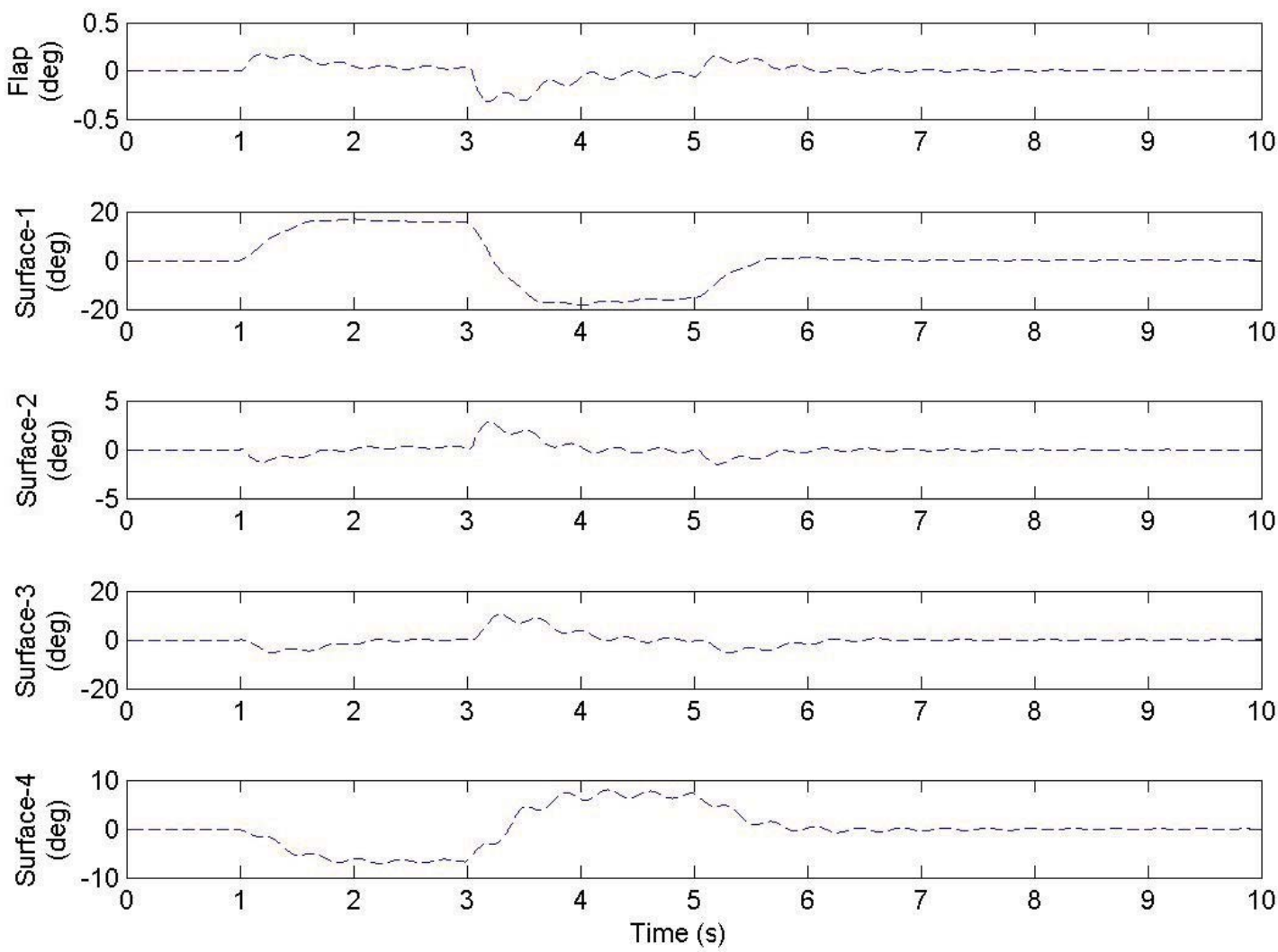

Figure 5. Surface response of the closed-loop X-56 aircraft to a pitch command doublet. 
high sampling rates.

A simulation of the X-56 aircraft was developed which incorporates a fiber optic strain measurements system. The 1500 strain measurements are passed to a modal filter which converts the measurements into modal displacements of the aircraft. The modal displacement estimates are used as feedback in an active control system to suppress the undesired aeroservoelastic states and to control the wing shape. The estimates are also usable to calculate the internal loads and can be used for system diagnostics.

Both $\mathcal{H}_{\infty}$ and $\mu$ control systems were synthesized. The control design goals were to control the wing shape and torsion, and to suppress the aeroservoelastic modes. The closed loop system was to have good performance with small overshoot and low settling time, and to be robust to noise and modeling uncertainty. Figure 6 displays the modal displacement of the first three aeroservoelastic modes in response to an asymmetric impulse disturbance. The top plot shows the modal displacement of the body-freedom-flutter mode. The body-freedom-flutter mode is the interaction of the heave mode and the symmetric wing bending mode. The middle plot shows displacement of the symmetric wing bending and torsional modes. The bottom plot shows the displacement of the antisymmetric wing bending and torsional modes.

In the figure, the system is initially open-loop resulting in the response growing in amplitude. At 1.6 seconds the control system is phased in over 1.0 seconds. The effect of the control system is suppression of the unstable modes.

\section{Future Research}

Future research plans include efforts to advance the design methodologies and approaches for integrated structural control of extremely lightweight flexible structures. The research includes investigations in modeling, sensing, and control. The research will identify shortfalls in these areas and in the existing tools and techniques, and assess how emerging analysis techniques and capabilities can best address these shortfalls.

\section{A. Sensing}

Advanced sensing technologies are of particular interest for aeroservoelastic control and are part of future $\mathrm{X}-56$ research plans. Two of the promising sensor systems are fiber optic strain-sensors and leading edge stagnation point sensors. These advanced sensors promise benefits for aeroservoelastic control over more traditional sensor systems including more robustness and redundancy. An understanding and quantification of these potential benefits is needed so that an appropriate balance between complexity and benefits of the advanced sensors can be achieved.

Fiber optic strain-sensing technology provides a capability to accurately estimate the mode shapes of a vehicle. Current research is using these estimates in feedback control to suppress unwanted structural vibration and to command wing shape. Future research will use the sensor system to map node lines and track structural mode frequencies and damping in real time. This information will be blended with other sensor measurements to provide a more robust active flutter suppression system. Researchers are anticipating the installation of a fiber optic strain-sensor system onto the X-56 aircraft. The system will enable in-flight experimentation of novel estimation and control schemes.

Among the challenges in incorporating fiber optic strain-sensors in control system design is to develop methods which capitalize upon the large number of measurements to allow multi-objective designs. Another challenge is to design the system to degrade gracefully when a subset of the fiber optic measurements is corrupted.

Leading Edge Stagnation Point (LESP) sensors measure the location of the chord wise stagnation point along the wing. One use of the measurements is to provide advanced indication of gust encounters. Combined with a feedback control system, the sensors will reduce undesirable system response to gust disturbances.

Using such sensors researchers have shown a correlation between leading edge stagnation point and separation point with unsteady aerodynamic loads. ${ }^{11}$ This correlation may be usable as feedback in control systems designed for flutter suppression. ${ }^{3}$ The X-56 aircraft has LESP sensors incorporated onto the wings. Researchers are anticipating the opportunity to conduct in-flight experimentation utilizing these sensors.

\section{B. Control Effectors}

Future research plans include investigation of novel effectors, optimal effector placement, and distributed control schemes. Active structural control requires high bandwidth control effectors with minimal hysteresis, 

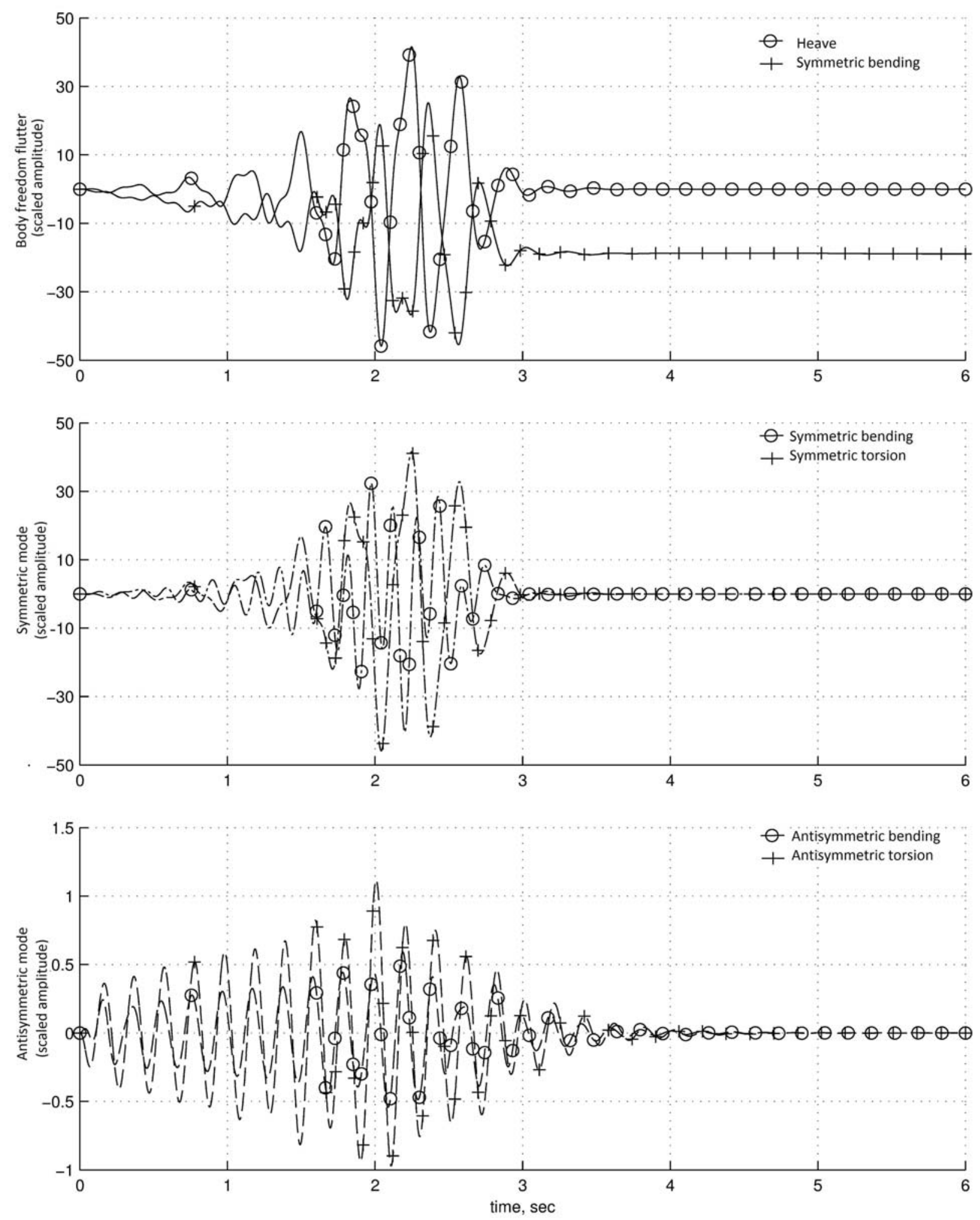

Figure 6. Modal displacement of the X-56 aircraft subject to asymmetric impulse disturbance. 
deadbands, and other nonlinearities. Emerging control effector technologies such as piezoelectric and shape memory alloys promise advantages over conventional effectors for active structural control. Investigation of these alternative effectors is part of the $\mathrm{X}-56$ research plans.

Optimal placement of control effectors is critical for effective mode suppression. Research plans include investigation of methods to determine the optimal placement of discrete surfaces. The plans also include investigation of the use of continuous mold line trailing edge surfaces. Such control surfaces provide distributed control along the entire wing. Distributed control enables multi-objective control designs to simultaneously achieve rigid body maneuvering, gust load alleviation, active structural mode suppression, and lift distribution to minimize drag.

Use of distributed control in conjunction with the advanced sensing technologies mentioned above will allow for more effective use of a smaller control force. As an example, if a fiber optic strain-sensor system provides accurate knowledge of the node lines, control could be applied to generate effective maneuvering without adversely exciting structural vibration modes. Conversely, structural mode suppression could be achieved while minimizing disturbance to the rigid body.

\section{Feedback Control Techniques}

Research on active control design methodologies continue as part of future research plans. Multiple methodologies have been proposed including linear parameter varying control, adaptive control, and fuzzy logic based control. The X-56 aircraft will be used to experiment with and compare the various approaches.

The goal is to design robust control systems for extremely lightweight flexible structures. Understanding the sensitivities of this class of system is crucial to being able to determine underlying required characteristics of any proposed control system.

\section{Conclusion}

The X-56 aircraft is a modular and versatile system. With replaceable wings and the ability to add a tail section or a third engine, the vehicle is capable of supporting a wide breadth of research.

Current research efforts are primarily focused on the suppression of unsteady aerodynamic modes such as body-freedom-flutter. The efforts include simulation studies of advanced sensors and novel control architectures, and flight experimentation using active control systems. Fiber optic strain-sensor systems are being incorporated into simulations to provide feedback for dynamic control systems intended to suppress unsteady aerodynamic modes. Various control design methodologies are being used to synthesize the control systems including $\mathcal{H}_{\infty}, \mu$, and LPV methodologies.

Future research plans continue experimentation with active control systems. The plans also include investigations into alternative control effectors and sensor systems. Plans include installation of a fiber optic strain-sensor system onto the X-56 aircraft. The system will enable investigations using strain measurements in feedback control schemes and new active control architectures. Novel control effectors utilizing piezoelectric or shape memory alloys placed in optimal locations will also enable novel control architectures. Novel wing and tail-section designs incorporating novel sensors and effectors can be incorporated into the X-56 aircraft for flight research. The modularity of the X-56 aircraft enables a wide breadth of research.

\section{References}

\footnotetext{
${ }^{1}$ Beranek, J., Nicolai, L., Buonanno, M., Burnett, E., Atkinson, C., Holm-Hansen, B., and Flick, P., "Conceptual Design of a Multi-Utility Aeroelastic Demonstrator," AIAA 2010-9350, 2010.

${ }^{2}$ Hjartarson, A., Seiler, P. J., and Balas, G. J., "LPV Aeroservoelastic Control Using the LPVTools Toolbox," AIAA 2013-4742, 2013

${ }^{3}$ Mangalam, S., Flick, P., and Brenner, M., "Higher level aerodynamics input for aeroservoelastic control of flexible aircraft," Vol. 6380, AIAA 2007-6380, 2007.

${ }^{4}$ Karpel, M., Moulin, B., and Idan, M., "Robust Aeroservoelastic Design With Structural Variations and Modeling Uncertainties," Journal of Aircraft, Vol. 40, No. 5, 2003, pp. 946-954.

5 "Lockheed Martin X-56A Tests Wing Design for HALE UAS," URL: http://www.uasvision.com/2012/02/03/ lockheed-martin-x-56a-tests-wing-design-for-hale-uas/ [cited 9 December 2013].

${ }^{6}$ Jordan, H., "X-56A Technology Demonstrator Achieves First Flight," URL: http://www.wpafb.af.mil/news/story_ print.asp?id=123358028 [cited 9 December 2013].

${ }^{7}$ Burnett, E. L., Atkinson, C., Beranek, J., Sibbitt, B., Holm-Hansen, B., and Nicolai, L., "NDOF Simulation Model for Flight Control Development with Flight Test Correlation," AIAA 2010-7780, 2010, pp. 2-5.
} 
${ }^{8}$ Chin, A. W., "State-space Model Development for the X-56A," ARMD Year End Report, NASA Dryden Flight Research Center, 2012 (Internal Document).

${ }^{9}$ Arvanitis, K. G., Kalogeropoulos, G., and Giotopoulos, S., "Guaranteed Stability Margins and Singular Value Properties of the Discrete-Time Linear Quadratic Optimal Regulator," IMA Journal of Mathematical Control and Information, Vol. 18, No. 3, 2001, pp. 299-324.

${ }^{10}$ Creech, G., "NASA Evaluates Fiber Optic Technology for Future Aircraft Efficiency," URL: http://www.nasa.gov/ centers/dryden/news/NewsReleases/2008/08-31.html\#.UpjdGXc6x7o [cited 9 December 2013].

${ }^{11}$ Mangalam, A. S. and Moes, T. R., "Real-Time Unsteady Loads Measurements Using Hot-Film Sensors," AIAA 2004-5371, 2004.

11 of 11 